Efeito de diferentes lâminas de irrigação por gotejamento nos danos de Spodoptera frugiperda (Lepidoptera: Noctuidae) em híbridos de milho (Zea mays L.)

\title{
Effect of different drip irrigation blades on Spodoptera frugiperda (Lepidoptera: Noctuidae) damage in maize hybrids (Zea mays L.)
}

\author{
Iracema Raquel Santos BEZERRA ${ }^{1}$, João Pedro Ferreira BARBOSA ${ }^{1}$, Rafael Lima Vieira dos \\ SANTOS $^{1}$, Rafael de Almeida LEITE ${ }^{1}$, Dacio Rocha BRITO ${ }^{2}$, Davi Bibiano BRITO ${ }^{3}$. \\ ${ }^{1}$ Graduandos em Ciências Biológicas; Universidade Estadual de Alagoas; iracemaraquel36@ hotmail.com; ${ }^{2}$ Professor \\ Titular do curso de Ciências Biológicas; Universidade Estadual de Alagoas, ${ }^{3}$ Professor Adjunto do Instituto de \\ Computação; Universidade Federal de Alagoas.
}

\begin{abstract}
Resumo - O milho (Zea mays L.) é uma das culturas de maior importância econômica mundial, entretanto, existem locais com baixos índices pluviométricos que deixam essa cultura sujeita ao déficit hídrico. Para amenizar este problema usa-se irrigação, podendo-se citar a de gotejamento como mais eficiente. No entanto, pragas diminuem a produtividade dessa cultura, principalmente a Spodoptera frugiperda. Assim, à medida que novos híbridos são produzidos, surge a carência de analisar a suscetibilidade deles às pragas. Com isso, objetivou-se neste trabalho, analisar o efeito da aplicação de irrigação por gotejamento em diferentes lâminas nos danos de $S$. frugiperda em híbridos de milho. A pesquisa foi realizada no Polo Tecnológico Agroalimentar de Arapiraca, com semeadura manual com 5 linhas de $5 \mathrm{~m}$ por parcela, sendo essas linhas separadas $0,80 \mathrm{~m}$ entre as mesmas e $0,10 \mathrm{~m}$ entre plantas. $\mathrm{O}$ delineamento experimental foi em blocos casualizados com três repetições dispostas em arranjo fatorial $4 \times 3$. Foram avaliadas todas as plantas das parcelas, exceto da bordadura. Os dados foram transformados em $\sqrt{x}$ e submetidos a ANOVA pelo teste $\mathrm{F}$ no software SISVAR, havendo significância, realizou-se teste de Tukey e regressão linear. Somente os híbridos diferiram pelo teste $\mathrm{F}$ entre os tratamentos, o híbrido Janor foi o que obteve menor média de dano. Conclui-se que houve diferença significativa quantos aos danos de $S$. frugiperda em híbridos, todavia não foi encontrada diferença entre as lâminas de irrigação por gotejamento nem sua interação com os híbridos.
\end{abstract}

Palavras-chave: Cultura, praga, suscetibilidade.

Abstract - The maize (Zea mays L.) is one of the world's most important crops. However, there are
places with low rainfall levels that leave this crop subject to water deficit. To alleviate this problem
irrigation is used, and drip irrigation can be cited as more efficient. However, pests affect the
productivity of this crop, especially Spdoptera frugiperda. Thus, as new hybrids are produced, the
lack of analyzing their susceptibility to pests arises. The objective of this study was to analyze the
effect of drip irrigation on different slides on S. frugiperda damage in maize hybrids. The research
was carried out at the Arapiraca Agro-Food Technological Pole, with manual sowing with 5 rows of 
$5 \mathrm{~m}$ per plot, these lines being $0,80 \mathrm{~m}$ apart and $0,10 \mathrm{~m}$ between plants. The experimental design was in randomized blocks with three replicates arranged in a $4 \times 3$ factorial arrangement. All plants of the plots were evaluated, except for the border. The data were transformed into $\sqrt{\mathrm{x}}$ and submitted to ANOVA by the F test in the SISVAR software, with significance, being performed the Tukey test and linear regression. Only the hybrids differed by the F test between the treatments and the Janor hybrid was the one that obtained less average damage. It was concluded that there was a significant difference in the number of $S$. frugiperda damages in hybrids, however, no difference was found between the drip irrigation slides and their interaction with the hybrids.

Keywords: Culture. Pest. susceptibility.

\section{Introdução}

O milho (Zea mays L.), planta pertencente à família Poaceae e ao gênero Zea. É uma das culturas de maior importância econômica no mundo, possuindo suma importância na alimentação animal e humana, devido ao seu rendimento em grãos, valor nutritivo, além da produção de forragem (LINS et al., 2017).

Segundo a Conab (2018), o Brasil é considerando o terceiro maior produtor mundial de milho, sua produção no ano de 2019 de estimada em seu terceiro levantamento distribuído entre a primeira e segunda safras, poderá atingir 91,1 milhões de toneladas. Em Alagoas, o milho é o uma das culturas de maior relevância, superada apenas pela cultura da cana-de-açúcar e feijão.

Os agricultores de Alagoas buscam semear o milho na estação chuvosa, quando existe condições de umidade no solo que proporcionem seu desenvolvimento, contudo, em alguns anos há baixos índices pluviométricos e a cultura fica sujeita a déficit híbrido (BARBOSA, 2017).

Segundo Araújo Neto et al. (2015), a irrigação torna disponível água para a cultura na quantidade e momentos adequados. Existem vários métodos de irrigação, entre eles, a irrigação por gotejamento. Este método possui várias vantagens, como maior eficiência no uso da água, maior produtividade, maior eficiência na adubação (fertilizantes podem ser aplicados através de água da irrigação), no controle fitossanitário, diminuição de mão-de-obra e redução de gastos com energia, além da possibilidade de automação (VILAS BOAS et al., 2011).

Contudo, fatores bióticos diminuem a produtividade e a qualidade do milho. Dentre estes, destacam-se as pragas, como a lagarta-do-cartucho (Spodoptera frugiperda) (J. E. Smith) (Lepidoptera: Noctuidae) (MICHELOTTO et al., 2013). É considerada a principal praga da cultura nas regiões tropicais e subtropicais da América (JUÁREZ et al., 2012). Além de ser uma espécie polífaga, infestando cerca de 180 espécies de plantas em sua zona de distribuição e também se há uma grande dificuldade no seu controle por métodos manuais (WAQUIL et al., 2013

Havendo condições favoráveis sua população aumenta rapidamente podendo destruir as folhas, o cartucho do milho, causar danos nas espigas e reduzir a produção final de grãos (CAMPOS; BOIÇA, 2012). Segundo Farias et al. (2018), novos híbridos são lançados no mercado e por isso necessitam-se observações a respeito dos possíveis danos das pragas aos mesmos, além da relação de fatores abióticos.

Desta maneira, considerando a importância da $S$. frugiperda como praga do milho, além da escassez de estudos desta praga em híbridos de milho em diferentes lâminas de irrigação por 
gotejamento, objetivou-se analisar o efeito da aplicação de diferentes lâminas de irrigação por gotejamento nos danos de $S$. frugiperda em híbridos de milho.

\section{Material e Métodos}

O experimento ocorreu no Polo Tecnológico Agroalimentar de Arapiraca, Sítio Bananeiras, Arapiraca - AL $\left(09^{\circ} 45^{\prime} 09^{\prime}\right.$ S S, 36 39' 40" W) em janeiro e março de 2018. O local possui clima As', tendo clima tropical e quente segundo a classificação de Köppen-Geiger e solo classificado como latossolo vermelho amarelo eutrófico (EMBRAPA, 2009).

Para cultivar os híbridos de ilho, o preparo do solo ocorreu convencionalmente por meio de aragem, realizou-se adubação segunda a análise do solo, utilizando para fundação e cobertura manualmente. A semeadura realizou-se também manualmente em 5 linhas por parcela, tendo $5 \mathrm{~m}$ linear cada, separadas $0,80 \mathrm{~m}$ entre as mesmas e 0,10 entre plantas. No decorrer da pesquisa realizou-se controle de plantas daninhas manualmente, além disso, conforme a necessidade e indicações técnicas utilizou-se agrotóxicos para o controle de pragas e doenças, inclusive o controle S. frugiperda com o inseticida Deltametrina, assim seguindo os tratos culturais normalmente utilizados pelos produtores.

Para a análise dos danos causados por S. frugiperda foram avaliadas todas as plantas das parcelas, com exceção das bordas devido ao efeito bordadura, ocorrendo duas avaliações na fase vegetativa, sendo a primeira avaliação subdivisão $\mathrm{V}(\mathrm{n})$ e a segunda após quinze dias na subdivisão pendoamento seguindo uma escala de notas visuais de 0 a 5 proposta por Carvalho (1970), correspondendo a: 0 - planta com folhas não-danificadas; 1 - planta apresentando folhas raspadas; 2 - planta apresentando folhas furadas; 3 - planta apresentando folhas rasgadas; 4 - planta apresentando lesão no cartucho, e 5 - planta apresentando cartucho destruído.

Utilizou-se blocos casualizados como delineamento experimental, havendo três repetições e tratamentos em arranjo fatorial $4 \times 3$. Foram avaliados quatro híbridos, Jabra, Javi, Janor e Jabrano submetidos a três lâminas de irrigação por gotejamento, lâmina de água de $2,5 \mathrm{~mm} / \mathrm{dia} ; 5,0 \mathrm{~mm} / \mathrm{dia}$ e $7,5 \mathrm{~mm} / \mathrm{dia}$.

Com os dados obtidos, realizou-se análise estatística do software Sisvar 5,6 (FERREIRA, 2011), fez-se transformação dos dados em $\sqrt{x}$, aplicando-se a análise de variância através do teste $F$, havendo resultados significativos, as médias das variáveis qualitativas foram comparadas pelo teste de Tukey $(p<0,05)$ e a variável quantitativa (irrigação) aplicou-se regressão linear.

\section{Resultados e Discussão}

Pela análise de variância, encontrou-se resultados significativos pelo teste $\mathrm{F}$ entre os híbridos a $5 \%$ de significância e bloco a $1 \%$ de significância, apresentando desta forma uma boa eficiência do delineamento experimental, como destaca Ferreira (2018). Já nas lâminas de irrigação e sua interação com os híbridos não se obteve resultados significativos, tanto a $1 \%$ e $5 \%$ de probabilidade (Tabela 1). 
Tabela 1. Resumo da análise de variância do efeito da aplicação das lâminas de irrigação por gotejamento nos danos de Spodoptera frugiperda em híbridos de milho. Dados transformados em $\sqrt{\mathrm{x}}$. Arapiraca, Alagoas, 2018.

\begin{tabular}{ccccc}
\hline FV & GL & SQ & QM & F \\
\hline Híbridos & 3 & 0.105472 & 0.035157 & $3.771^{*}$ \\
Lâminas de irrigação (LI) & 2 & 0.033177 & 0.016588 & $1.779^{\text {ns }}$ \\
HxLI & 6 & 0.069505 & 0.011584 & $1.242^{\text {ns }}$ \\
Bloco & 2 & 0.192316 & 0.096158 & $10.314^{* *}$ \\
Resíduo & 22 & 0.205113 & 0.009323 & \\
\hline Total & 3 & 0.605583 & & \\
\hline CV: $6,61 \%$ & & & & \\
\hline
\end{tabular}

*** Significativo a 1 e $5 \%$ de probabilidade, respetivamente, pelo teste $\mathrm{F} .{ }^{\text {ns }}$ Não significativo.

Nais, Busoli e Michelotto (2013) ao estudarem o comportamento de híbridos isogênicos de milho em relação aos danos de $S$. frugiperda em duas localidades e épocas de semeadura, observaram que os híbridos na maioria das vezes não diferiram estatisticamente, todavia o híbrido Impacto obteve menor nota de dano. Já neste estudo analisando outros híbridos, o híbrido Janor obteve 1,39 como média de dano, indicando assim maior resistência a S. frugiperda, diferindo estatisticamente do híbrido Jabra que obteve a nota de 1,53 , tendo o menor índice de resistência a $S$. frugiperda, enquanto os demais híbridos não diferiram estatisticamente entre si (Tabela 2).

Tabela 2. Danos foliares de Spodoptera frugiperda em híbridos de milho considerando todos os níveis de irrigação. Dados transformados em $\sqrt{x}$. Arapiraca, Alagoas, 2018.

\begin{tabular}{cc}
\hline Híbrido & Nota média de dano \\
\hline Janor & $1,39 \mathrm{~b}$ \\
AG 1051 & $1,42 \mathrm{ab}$ \\
Jabrano & $1,49 \mathrm{ab}$ \\
Jabra & $1,53 \mathrm{a}$ \\
\hline
\end{tabular}

Médias seguidas de mesma letra não diferem estatisticamente pelo teste de Tukey no nível de 5\% de significância.

Enquanto os níveis de irrigação não influenciaram nos danos de $S$. frugiperda. Farias et al. (2018) ao pesquisarem a ocorrência da mesma praga em espigas de híbridos de milho submetidos também a diferentes lâminas de irrigação por gotejamento também não obtiveram resultados significativos.

Resultados significativos a respeito da irrigação no controle de pragas foram observados nos estudos de Françoso et al. (2010) na cultura do café, sendo observada menor incidência do inseto-praga nas maiores lâminas de irrigação, com índices inferiores a 5\% de incidência. Já nos estudos de Pannuti et al. (2015) ao analisarem o efeito de fertirrigação nitrogenada na incidência de 
Revista da Universidade Estadual de Alagoas/UNEAL

e-ISSN 2318-454X, Ano 11, Vol. 11(2), 2019

Mahanarva fimbriolata em cana-de-açúcar, observou-se aumento na ocorrência da praga com utilização excessiva de fertirrigação. Pannuti et al. (2013) observaram que também a fertirrigação nitrogenada em cana-de-açúcar aumenta a ocorrência de Diatraea saccharalis.

\section{Conclusão}

Houve diferença significativa quanto aos danos causados por $S$. frugiperda em diferentes híbridos de milho, sendo o híbrido Janor se observa a menor nota média de dano, todavia não foi encontrada diferença entre os níveis de irrigação por gotejamento e também sua respectiva interação com os híbridos.

\section{Agradecimentos}

Ao Polo Tecnológico Agroalimentar de Arapiraca e ao Grupo de Pesquisa Plantas Forrageiras para o Semiárido.

\section{Conflito de Interesse}

Os autores não declararam conflito de interesse para esse manuscrito.

\section{Referências}

ARAÚJO NETO, R. A.; SARMENTO, P. L.; FERREIRA JÚNIOR, R. A.; SILVA, M. B. P.; ROCHA, A. E. Q.; TEODORO, I. Desempenho de um sistema de irrigação por gotejamento em cana-de-açúcar. Ciência Agrícola, v. 13, n. 1, p. 15-18, 2015.

BARBOSA, W. S. S. Milho cultivado sob diferentes lâminas de irrigação e adubação nitrogenada. 2017. 116f. Dissertação (Mestrado em Agronomia) - Centro de Ciências Agrárias, Universidade Federal de Alagoas, Rio Largo, 2017.

CARVALHO, R. L. P. Danos, flutuação da população, controle e comportamento de Spodoptera frugiperda (J. E. Smith, 1797) e susceptibilidade de diferentes cultivares de milho, em condições de campo. 1970. 170f. Tese (Doutorado em Agronomia) - Escola Superior de Agricultura "Luiz de Queiroz”, Universidade de São Paulo, Piracicaba, 1970. 


\section{Revista Ambientale}

Revista da Universidade Estadual de Alagoas/UNEAL e-ISSN 2318-454X, Ano 11, Vol. 11(2), 2019

CAMPOS, A. P.; BOIÇA JÚNIOR, A. L. Lagartas de Spodoptera frugiperda (J. E. SMITH) (Lepidoptera: Noctuidae) submetidas a diferentes concentrações de óleo de nim. Revista Brasileira de Milho e Sorgo, v.11, n.2, p.137-144, 2012.

CONAB. Acompanhamento da safra brasileira de grãos - 2018. 2018. Disponível em <https://www.conab.gov.br/info-agro/safras/graos/boletim-da-safra-degraos/item/download/23679_041c465fb71e41cf382825c6b8c43623>. Acesso em 21 de dezembro de 2018.

EMBRAPA. Mapa exploratório do reconhecimento do solo em Arapiraca - AL. 2009. Disponível em:< http://www.uep.cnps.embrapa.br/solos/index.php?link=al $>$. Acesso em 12 de novembro de 2018.

FERREIRA, D. F. Sisvar: a computer statistical analysis system. Ciência e Agrotecnologia, v. 35, n. 6, p. 1039-1042, 2011.

FARIAS, L. R. A.; BARBOSA, J. P. F.; SILVA, P.; SILVA JUNIOR, I. P.; CUNHA, F. S. A.; COSTA, R. S. C.; BRITO, D. R.; BRITO, D. B. Incidência de Spodoptera frugiperda (Lepidoptera: Noctuidae) em espigas de híbridos de milho (Zea mays L.) submetidos a diferentes lâminas de irrigação. Revista Craibeiras de Agroecologia, v. 3, n. 1, 2018.

LINS, F. J. A.; FERREIRA, P. V.; ASSUNÇÃO, M. C.; SANTOS, D. F.; CARVALHO, A. P. V.; SANTOS, N. E. A. Crescimento de genótipos experimentais de milho em função de doses crescentes de nitrogênio. Ciência Agrícola, v. 15, n. 2, p. 19-27, 2017.

NAIS, J.; BUSOLI, A. C.; MICHELETTO, M. D. Comportamento de híbridos de milho transgênicos e respectivos híbridos isogênicos convencionais em relação à infestação de Spodoptera frugiperda (J. E. Smith,1727) (Lepidoptera: Noctuidae) em duas localidades épocas de semeadura. Arquivo Instituto Biológico., v.80, n.2, p.159-167, 2013.

PANNUTI, L. E. R.; BALDIN, E. L. L.; GAVA, G. J. C.; KOLLN, O. T. Efeitos da fertirrigação sobre a ocorrência e danos de Mahanarva fimbriolata (Stål) (Hemiptera: Cercopidae) em cana-deaçúcar. Arquivos do Instituto Biológico, v. 82, n. 1, p. 1-8, 2015.

PANNUTI, L. E. R.; BALDIN, E. L. L.; GAVA, G. J. C.; KOLLN, O. T.; CRUZ, J. C. S. Danos do complexo broca-podridão à produtividade e à qualidade da cana-de-açúcar fertirrigada com doses de nitrogênio. Pesquisa Agropecuária Brasileira, v. 48, n. 4, p. 381-387, 2013.

VILAS BOAS, R. C. Viabilidade econômica do uso do sistema de irrigação por gotejamento na cultura da cebola. Ciência e Agrotecnologia, v. 35, n. 4, p. 781-788, 2011.

WAQUIL, J. M.; DOURADO, P. M.; CARVALHO, R. A.; OLIVEIRA, W. S., BERGER, G. U.; HEAD, G. P.; MARTINELLI, S. Manejo de lepidópteros-praga na cultura do milho com o evento Bt piramidado Cry1A.105 e Cry2Ab2. Pesquisa Agropecuária Brasileira, v. 48, n. 12, p. 15291537, 2013. 